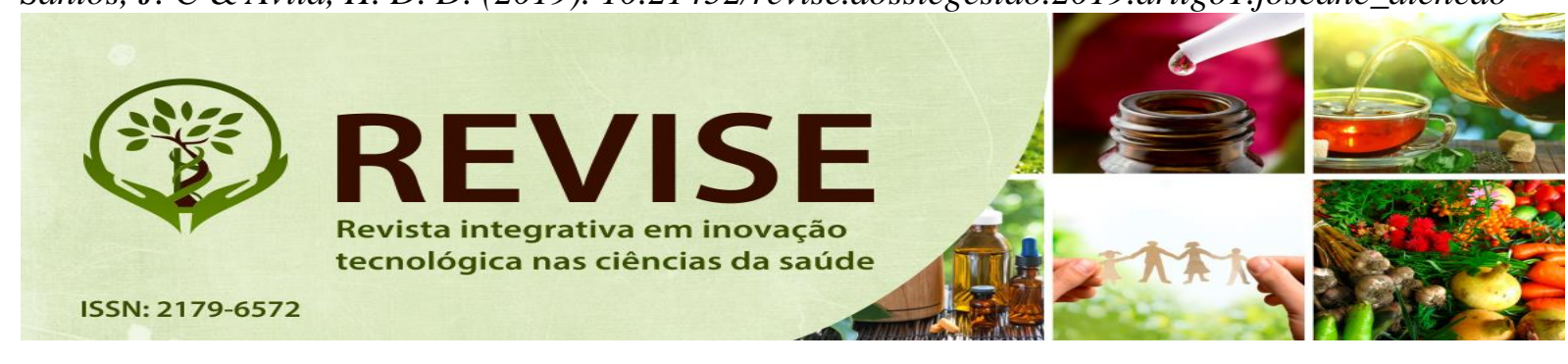

\title{
ATENÇÃO PRIMÁRIA \\ NA POLÍTICA DA SAÚDE E O PAPEL DO ASSISTENTE SOCIAL
}

\author{
Joseane Conceição Santos \\ UFRB \\ Heleni Duarte Dantas de Ávila \\ UFRB
}

\section{RESUMO}

Este estudo tem como objetivo conhecer o papel do Serviço Social na Atenção Primária à Saúde. Trata-se de um estudo descritivo desenvolvido por meio de uma revisão sistemática da literatura, analisando livros e artigos que tratem da temática abordada. O Assistente Social enfrenta na atualidade o desafio de não ser apenas um profissional executivo, mas que ultrapassa os limites das atividades burocráticas e tarefas estabelecidas trabalhando com as expressões da questão social, bem como com planejamento, gestão e implementação de políticas, programas e projetos que viabilizem o acesso aos serviços de saúde para os usuários. Assim, para o fortalecimento da Atenção Primária à saúde, o Assistente Social deve com um olhar crítico, atuar como um mediador nas questões em saúde, orientando, procedendo aos encaminhamentos necessários, atuando com educação em saúde, junto ao controle social/democrático, tendo como meta o cumprimento das diretrizes e princípios do Sistema Único de Saúde.

\section{Descritores}

Política de Saúde, Serviço Social, Atenção Primária.

\begin{abstract}
This study aims to know the role of Social Service in Primary Health Care. It is a descriptive study developed through a systematic review of the literature, analyzing books and articles that deal with the subject matter. The Social Worker faces today the challenge of not only being an executive professional, but going beyond the limits of bureaucratic activities and established tasks, working with the expressions of the social question, as well as with planning, management and implementation of policies, programs and projects that access to health services for users. Thus, in order to strengthen primary health care, the Social Worker must take a critical view, act as a mediator in health issues, orienting, proceeding with the necessary referrals, working with health education, along with social / democratic control as a goal to comply with the guidelines and principles of the Unified Health System.
\end{abstract}

\section{Descriptors}

Health Policy, Social Work, Primary Care.

Política de saúde. Revista Revise, vol. 3, Dossiê de Gestão em Saúde, p.1-17. 

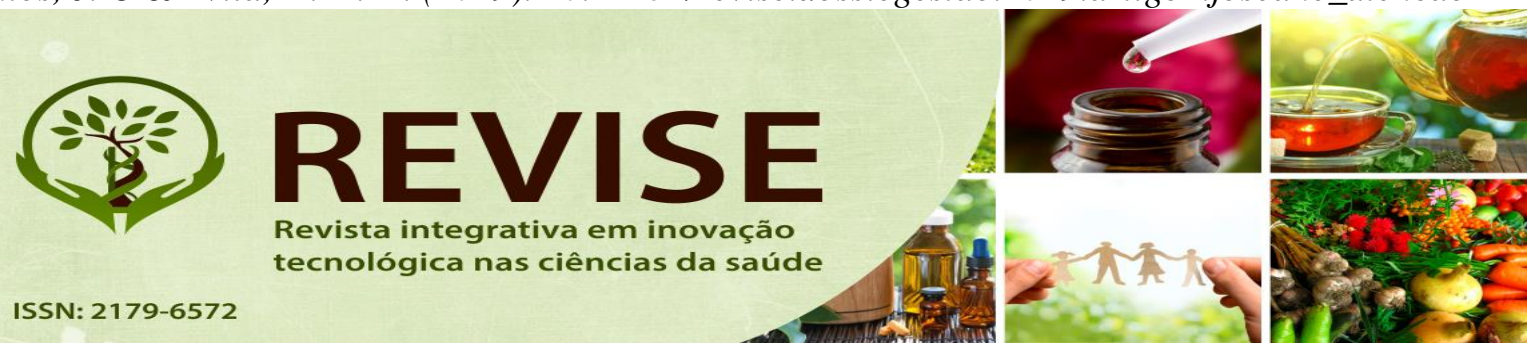

\title{
INTRODUÇÃO
}

As considerações desenvolvidas neste trabalho visam analisar qual é o papel do Assistente Social na Política de Saúde, especificamente dentro da estratégia de organização dos serviços denominada Atenção Primária à Saúde, ou seja, como esse profissional pode atuar nesta área da saúde que é a porta de entrada dos usuários no Sistema Único de Saúde SUS. Assim, o estudo abordou como o profissional do serviço social pode contribuir para o fortalecimento da Atenção Primária como parte de uma equipe interprofissional. Desta forma, o objetivo geral deste estudo é conhecer o papel do profissional de serviço social na Atenção Primária à Saúde.

Segundo a Portaria n 2.436, de 21 de setembro de 2017, a Atenção básica é:

\begin{abstract}
Art. $2^{\circ}$ A Atenção Básica é o conjunto de ações de saúde individuais, familiares e coletivas que envolvem promoção, prevenção, proteção, diagnóstico, tratamento, reabilitação, redução de danos, cuidados paliativos e vigilância em saúde, desenvolvida por meio de práticas de cuidado integrado e gestão qualificada, realizada com equipe multiprofissional e dirigida à população em território definido, sobre as quais as equipes assumem responsabilidade sanitária. $\S 1^{\circ}$ A Atenção Básica será a principal porta de entrada e centro de comunicação da RAS, coordenadora do cuidado e ordenadora das ações e serviços disponibilizados na rede. $\S 2^{\circ}$ A Atenção Básica será ofertada integralmente e gratuitamente a todas as pessoas, de acordo com suas necessidades e demandas do território, considerando os determinantes e condicionantes de saúde.
\end{abstract}

Assim, a Atenção Primária em Saúde - APS e a Atenção Básica - AB, segundo a supramencionada portaria são considerados termos equivalentes, associando a ambos os princípios e as diretrizes definidas na Portaria que estabelece a Politica Nacional de Atenção Básica no âmbito do SUS. Desta forma, a $\mathrm{AB}$, nada mais é que uma intervenção continua e sistematizada dos cuidados com a saúde integrando ações preventivas e curativas, bem como soluções para agravos maiores. Não obstante, tal estratégia de saúde ainda está longe de ser aquilo idealizado pelos princípios previstos na Reforma Sanitária, e consoante disposto no marco legal do Sistema Único de Saúde.

Existe uma sub oferta dos serviços de saúde, em particular nas ações de média e alta complexidade, deixando um grande número de usuários do sistema sem o atendimento necessário. Destaca-se neste contexto, a importância da presença do Assistente Social, que

Política de saúde. Revista Revise, vol. 3, Dossiê de Gestão em Saúde, p.1-17. 

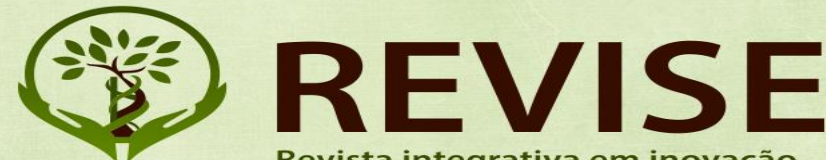

Revista integrativa em inovação tecnológica nas ciências da saúde

ISSN: $2179-6572$

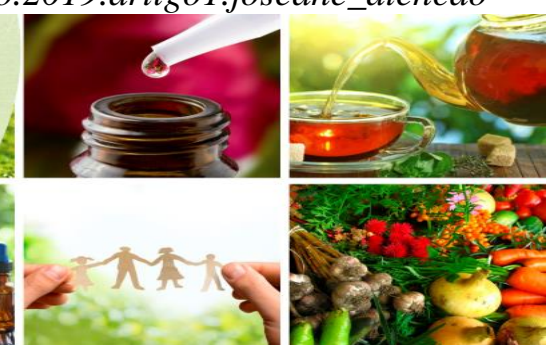

tem como foco principal de sua intervenção profissional as expressões da questão social, devendo pautar a sua ação com base nos princípios estabelecidos pelo Movimento da Reforma Sanitária, consolidados pelo Sistema Único de Saúde - SUS (MATTA e MOROSINI, 2009).

As Unidades Básicas de Saúde são consideradas como o primeiro acesso, ou porta de entrada, para atendimento a saúde. Segundo o que preconiza o SUS, a saúde não se resume a ausência de doença, mas a toda uma gama de ações que se propõem a "formulação e execução de políticas econômicas e sociais que visem à redução de riscos de doenças e de outros agravos e no estabelecimento de condições que assegurem acesso universal e igualitário às ações e aos serviços para a sua promoção, proteção e recuperação ${ }^{1}$ ".

A política de saúde no Brasil, desde o nascimento do SUS, vive um dilema entre dois modelos de atenção em saúde: de um lado o modelo privatista e de outro o modelo preconizado pelo Movimento da Reforma Sanitária, o da saúde coletiva. Estes modelos contraditórios, acabam por prejudicar a implementação do SUS. Segundo Paim (2003), os modelos assistenciais ou modos de intervenção em saúde constituem “[...] combinações tecnológicas estruturadas em função de problemas de saúde (danos e riscos) que compõem o perfil epidemiológico de uma dada população e que expressam necessidades sociais de saúde, historicamente definidas".

Ante este cenário, existe um grande desafio aos profissionais de saúde: reafirmar o que foi estabelecido pelo Movimento da Reforma Sanitária, e contribuir para a implementação do SUS em conformidade com o seu marco legal, construindo um bloco contra hegemônico que garanta a saúde como direito de cidadania.

A conjuntura política brasileira segue com o mercado influenciando em grande escala as políticas sociais, o que acaba rebatendo na efetivação do SUS. O cenário que se vê é de filas, atendimentos deficitários, terceirizações, precarizações dos vínculos de trabalho, burocratização, desrespeito ao princípio de equidade na alocação de recursos públicos ou

\footnotetext{
${ }^{1}$ http://www.planalto.gov.br/ccivil_03/leis/L8080.htm. Acessado em 09/06/2018. Lei $\mathrm{n}^{\circ} \quad 8.080$ de 19 de setembro de 1990. ${ }^{2}[\ldots]$ O plenário do Conselho Nacional de Saúde (CNS) reconheceu como profissionais de saúde de nível superior as seguintes categorias: assistentes sociais, biólogos, profissionais de educação física, enfermeiros, farmacêuticos, fonoaudiólogos, médicos, médicos veterinários, nutricionistas, odontólogos, psicólogos e terapeutas ocupacionais. (RESOLUÇÃO CNS Nº 218, DE 06 DE MARÇO DE 1997).
}

Política de saúde. Revista Revise, vol. 3, Dossiê de Gestão em Saúde, p.1-17. 


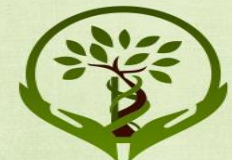

ISSN: $2179-6572$

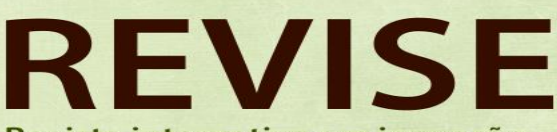

Revista integrativa em inovação tecnológica nas ciências da saúde

escassez dos mesmos e falta de valorização dos recursos humanos. É necessário fazer valer o

Art. 196. A saúde é direito de todos e dever do Estado, garantido mediante políticas sociais e econômicas que visem à redução do risco de doença e de outros agravos e ao acesso universal e igualitário às ações e serviços para sua promoção, proteção e recuperação.

O Assistente Social possui uma inserção histórica no campo da saúde, deve atuar com um olhar crítico, e pautar a sua intervenção embasada no projeto ético político profissional, visando à promoção, prevenção e recuperação da saúde dos usuários do sistema. $\mathrm{O}$ profissional do Serviço Social, segundo os Parâmetros para Atuação do Assistente Social na Saúde (CFESS, 2009) tem como competências: atendimento direto aos usuários; ações sócio assistenciais; ações de articulação com a equipe de saúde; ações socioeducativas; mobilização, participação e controle social; investigação, planejamento e gestão; assessoria, qualificação e formação profissional.

O Assistente Social é reconhecido como profissional de saúde segundo as Resoluções do Conselho Nacional de Saúde ${ }^{\circ}$ 218/1997 e do Conselho Federal de Serviço Social $n^{\circ}$ 383/1999², o que reafirma a importância da inserção deste profissional nesta politica pública.

Este trabalho tentou responder a seguinte pergunta: Como o Assistente social pode contribuir para o fortalecimento da Atenção Primária à Saúde?

\section{MÉTODOS DO ESTUDO}

O método de pesquisa utilizado foi à revisão integrativa da literatura, envolvendo sistematização e posterior publicação dos resultados. Principais autores considerados Santini (2009), Lavras (2011), Marques (2016), Hoffmann, Oliveira e Reidel (2017), Camargo (2011) e Sodré (2014), Vasconcelos (2006), Bravo (2006), Iamamoto (2008) e Paim (2003).

\footnotetext{
${ }^{2}$ [...] O plenário do Conselho Nacional de Saúde (CNS) reconheceu como profissionais de saúde de nível superior as seguintes categorias: assistentes sociais, biólogos, profissionais de educação física, enfermeiros, farmacêuticos, fonoaudiólogos, médicos, médicos veterinários, nutricionistas, odontólogos, psicólogos e terapeutas ocupacionais. (RESOLUÇÃO CNS Nº 218, DE 06 DE MARÇO DE 1997).
}

Política de saúde. Revista Revise, vol. 3, Dossiê de Gestão em Saúde, p.1-17. 


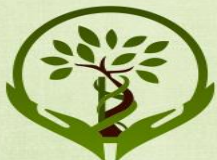

ISSN: $2179-6572$

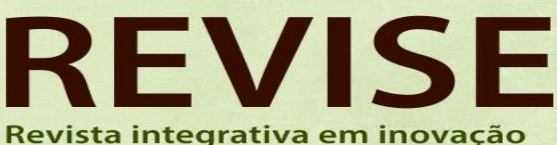

Revista integrativa em inovação tecnológica nas ciências da saúde

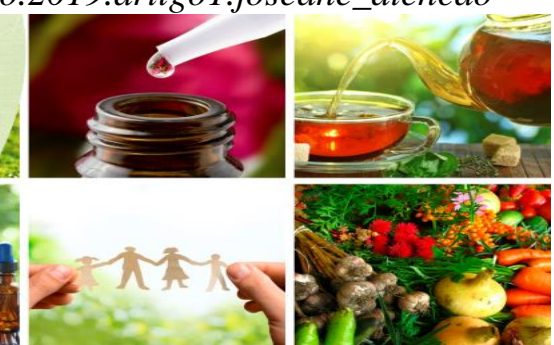

Trata-se de uma pesquisa bibliográfica descritiva desenvolvida por meio de uma revisão sistemática da literatura analisando livros e artigos que tratem da temática abordada. Segundo Galvão, Sawada e Trevizan (2004, p. 550), esse tipo de revisão gira em torno de estudos que tenham sido realizados com o mesmo propósito e agrupam o máximo de informações similares sobre o mesmo tema; É uma "síntese rigorosa de todas as pesquisas com uma questão especifica”.

A busca bibliográfica foi realizada na base de dados da Biblioteca Virtual de Saúde (BVS) e Scientific Eletronic Library On-line (SCIELO), tendo como descritores Política de Saúde, Serviço Social e Atenção Primária. Através da pesquisa, foram encontrados o total de 30 (trinta) artigos, mas foram utilizados 10 (dez) publicações gratuitas, disponíveis na integra em português.

Foram incluídos artigos originais de pesquisas, textos completos, dissertações onde o estudo fosse voltado para a temática em questão, e foram excluídos estudos que não pontuavam sobre o tema, artigos em outros idiomas, resumos e reportagens.

\section{ANTECEDENTES DOS SUS}

A constituição da República Federativa do Brasil instituiu em 5 de Outubro de 1988 uma nova forma de organizar serviços de saúde denominado Sistema Único de Saúde - SUS. A Constituição Federal de 1988 estabeleceu a saúde como um direito de todos e um dever do estado, formando a base para o sistema público e universal, que visa à promoção da justiça social e superar as desigualdades na assistência à saúde da população.

O capitulo II da Seguridade social, preceitua que a saúde deve ser garantida mediante políticas sociais e econômicas que visem à redução do risco de doenças e outros agravos e ao acesso universal e igualitário as ações e serviços para sua promoção, proteção e recuperação (SANTINI, 2009).

Para chegar ao texto constitucional um percurso histórico importante foi trilhado, impulsionado por alguns problemas existentes na forma de atenção a saúde no Brasil. Os principais problemas apresentados, anteriormente eram: acesso restrito; ênfase nas ações curativas; o Ministério da Saúde era responsável apenas pelas ações de prevenção,

Política de saúde. Revista Revise, vol. 3, Dossiê de Gestão em Saúde, p.1-17. 

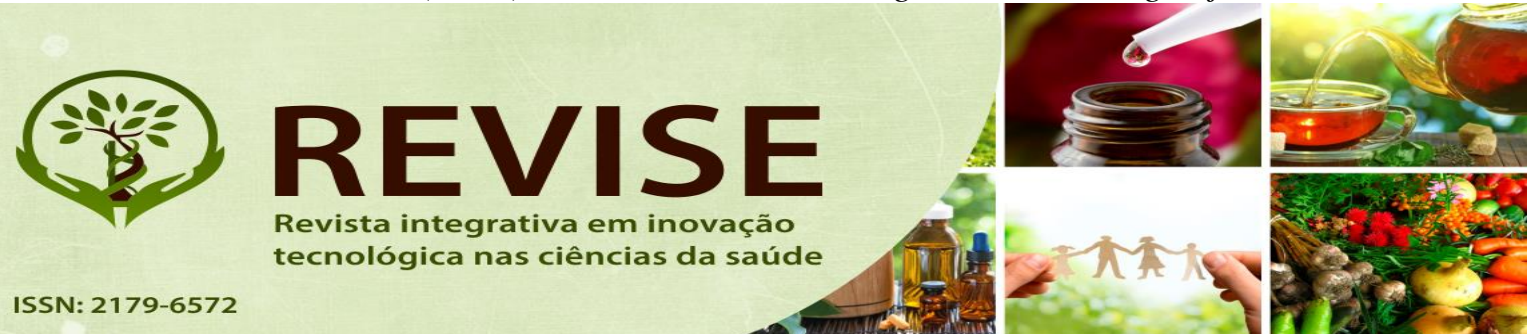

ISSN: $2179-6572$

Revista integrativa em inovação tecnológica nas ciências da saúde

saneamento e vacinação, as ações de cura e tratamento eram atribuídas a previdência social ou

a caridade para aqueles que não possuíam vínculo formal de trabalho; O ministério da

Previdência era o responsável pela rede hospitalar e pelas ações de cura e prevalência da medicina privada em detrimento das ações públicas.

Assumpção (2007), acerca do percurso histórico da saúde pública brasileira, afirma que:

Inicialmente o sistema de atenção à saúde estava ligado às caixas de Aposentadorias e Pensões (CAPs) que foram substituídas em 1923 pelos Institutos de Aposentadorias e Pensões (IAPs), fato que é considerado um marco da medicina previdenciária. A política de saúde esboçada a partir dos anos 1930 foi consolidada no período de 1945 a 1964, quando estava focada na racionalização administrativa e na atribuição de maior sofisticação às campanhas sanitárias (ASSUMPÇÃO, p.19, 2007).

Em um período posterior, no período da Ditadura Militar, Bravo (2006) apud Assumpção (2007), aponta que:

No período de 1964 a 1974, a política de saúde desenvolveu-se privilegiado o setor privado, devido às influencias da ditadura militar que forjou em muito as forças democráticas. Nos anos seguintes, prossegue a tensão entre os interesses dos setores estatal e empresarial e a emergência do movimento sanitário.

Em virtude desta situação de desigualdade os profissionais de saúde, juntamente com movimentos sociais organizados, a exemplo do movimento das donas de casa da Zona Leste de São Paulo, passaram a lutar por mudanças que garantissem a sociedade maior equidade de direitos, que foi o Movimento da Reforma Sanitária.

Como culminância de toda essa mobilização, em 1986 é realizada a VIII Conferência Nacional de Saúde, que contou, pela primeira vez com a participação da sociedade civil organizada e teve como tema central: Saúde é um direito de todos e um dever do Estado.

Após a VIII Conferência, foi criado um grupo de trabalho para redigir a proposta do texto constitucional acerca da saúde, e foi criado o SUDS - Sistema Unificado e Descentralizado de Saúde, que funcionou como estratégia ponte para viabilizar as condições de criação e implementação do SUS.

Assim, o SUS nasce como resultante de lutas e apelos da Sociedade civil.

O SUS é a maior política social brasileira nos últimos vinte cinco anos. E por ser uma política social universal, tem: ampla dimensão em termos da rede de serviço público e convênios com o setor filantrópico e privado, que vai da atenção primária à média e alta complexidade; grande estrutura de gestão nas três esferas

Política de saúde. Revista Revise, vol. 3, Dossiê de Gestão em Saúde, p.1-17. 

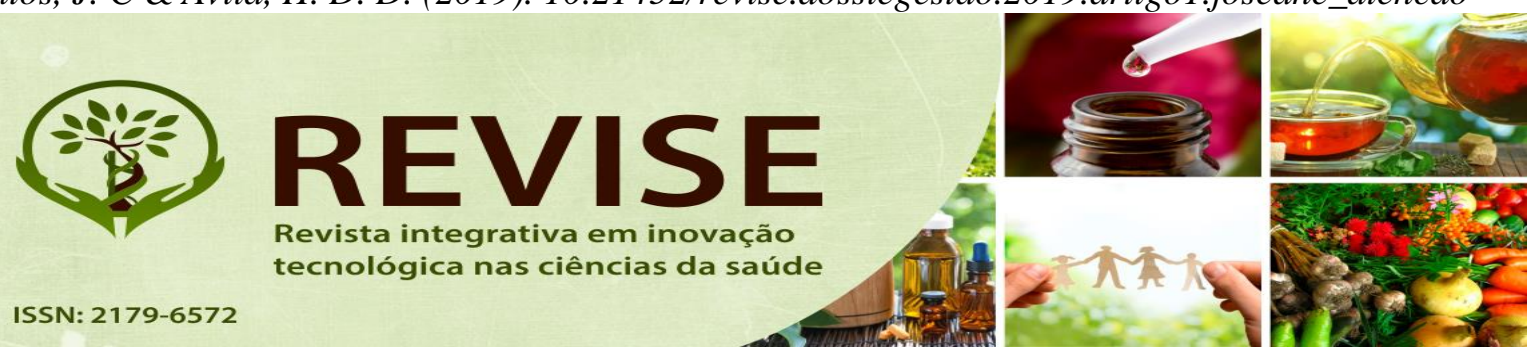

$\cos ^{2} \mathrm{i}$

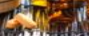

de governos; um financiamento vinculado que só é menor em relação ao da educação; envolve uma série de indústrias para produzir seus suprimentos que vão desde o algodão, aos medicamentos e equipamentos médico-hospitalares; milhares de trabalhadores de diferentes áreas; uma grande rede de escolas e universidades públicas e privadas para formar os profissionais e realizar pesquisas; inúmeros institutos e laboratórios públicos de pesquisas e produção de medicamentos, vacinas e insumos. É por esta dimensão que o SUS é uma política social extremamente visada, disputada e tensionada por vários segmentos e interesses socioeconômicos e políticos. (Krüger, 2014, p. 224).

Contudo, para que o SUS seja efetivado consoante o que foi preconizado pelo Movimento da Reforma Sanitária, ainda está longe de ser realidade e possui um longo caminho a ser percorrido. Os modelos privatistas e da reforma sanitária ainda permanecem em disputa, cabendo aos profissionais e usuários fazer valer o SUS real/legal.

\section{ATENÇÃo PRIMÁRIA À SAÚDE}

A Atenção Básica de Saúde hoje conhecida como Atenção Primária à Saúde - APS, segundo Matta e Morosini (2017) incorpora os princípios da Reforma Sanitária. O Sistema Único de Saúde (SUS) adota a designação Atenção Básica à Saúde - ABS para enfatizar a reorientação do modelo assistencial, a partir de um sistema universal e integrado de atenção à saúde.

A ideia de Atenção Primária à Saúde foi utilizada como forma de organização dos sistemas de saúde pela primeira vez no chamado Relatório Dawnson, em 1920. Esse relatório organizava o modelo de atenção em centros de saúde primários e secundários, serviços domiciliares, serviços suplementares e hospitais de ensino, e uma vez organizados desta forma a maior parte dos problemas de saúde deveriam ser resolvidos por médicos com formação em Clínica Geral.

A Atenção Básica caracteriza-se por um conjunto de ações de saúde, no âmbito individual e coletivo, que abrange a promoção e a proteção da saúde, a prevenção de agravos, o diagnóstico, o tratamento, a reabilitação, redução de danos e a manutenção da saúde, com o objetivo de desenvolver uma atenção integral que impacte na situação de saúde e autonomia das pessoas, e nos determinantes e condicionantes de saúde das coletividades. Nesse primeiro nível a promoção em saúde é desenvolvida por meio do exercício de práticas de cuidado e

Política de saúde. Revista Revise, vol. 3, Dossiê de Gestão em Saúde, p.1-17. 


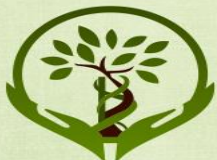

ISSN: $2179-6572$

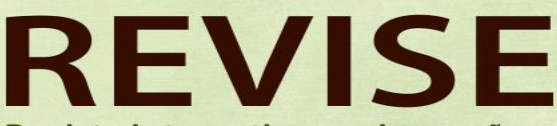

Revista integrativa em inovação tecnológica nas ciências da saúde
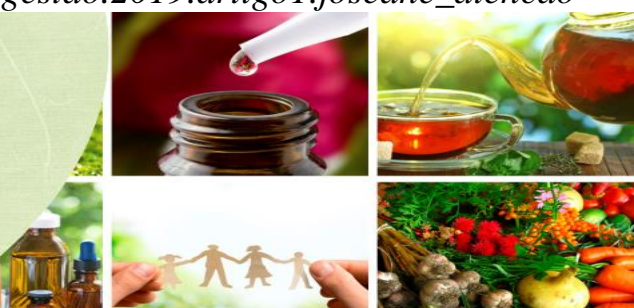

gestão, democráticas e participativas, sob a forma de trabalho em equipe, dirigidas a populações de territórios definidos, pelas quais assume a responsabilidade sanitária, considerando a dinamicidade existente no território em que vivem essas populações. Utiliza tecnologias de cuidado complexas e variadas que devem auxiliar no manejo das demandas e necessidades de saúde de maior frequência e relevância em seu território, observando critérios de risco, vulnerabilidade, resiliência e o imperativo ético de que toda demanda, necessidade de saúde ou sofrimento deve ser acolhida. (Ministério da Saúde, Portaria 2448, de 2011)

A utilização do termo "Atenção Primária a Saúde" - APS expressa comumente o entendimento de uma atenção ambulatorial não especializada, ofertada através de unidades de saúde de um sistema, que se caracteriza pelo desenvolvimento de conjunto bastante diversificado de atividades clinicas de baixa densidade tecnológica, o que inclui, em muitos países, como no Brasil, as atividades de saúde pública.

O senso comum entende essas unidades como espaços onde se dá, ou deveria se dar, majoritariamente, o primeiro contato dos usuários com o sistema e onde existe capacidade para a resolução de grande parte dos problemas de saúde por eles apresentados. (Lavras, 2011).

A Atenção Primária em Saúde é considerada a porta de entrada preferencial do Sistema Único de Saúde - SUS, o primeiro contato do paciente em busca da intervenção médica para o agravo. Nesse sistema, vários serviços em saúde podem ser resolvidos como vacinação, cuidados com a saúde da mulher e da criança, acompanhamento de hipertensos e diabéticos, já os problemas que não podem ser completamente resolvidos são encaminhados para consultas com especialistas, realização de exames ou atendimento nas Unidades de Pronto Atendimento, hospitais, Centros de Atenção Psicossocial, entre outros.

\section{SERVIÇO SOCIAL NA POLÍTICA DE SAÚDE}

O Serviço Social é uma profissão regulamentada e amparada na Lei $\mathrm{N}^{\circ}$ 8.662/93, no Código de Ética Profissional, Resolução CFESS no 273 de 13 de março de 1993 e nas Diretrizes Curriculares da ABEPSS/96 (Associação Brasileira de Ensino e Pesquisa em Serviço Social), com caráter generalista.

Política de saúde. Revista Revise, vol. 3, Dossiê de Gestão em Saúde, p.1-17. 

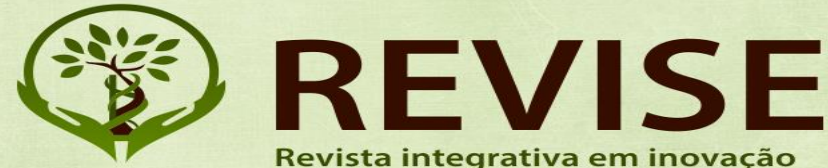

Revista integrativa em inovação tecnológica nas ciências da saúde

ISSN: $2179-6572$

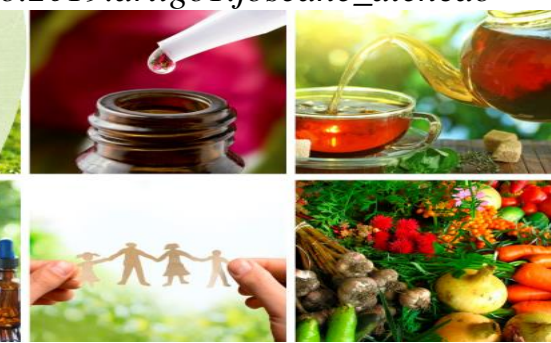

Em 1999 o Conselho Federal de Serviço Social por meio da Resolução nº. 383/99 de

29 de Março de 1999, "Caracteriza o assistente social como profissional da Saúde”, conforme trecho a seguir:

Considerando que atribui-se ao assistente social, enquanto profissional de saúde, a intervenção junto aos fenômenos socioculturais e econômicos que reduzam a eficácia dos programas de prestação de serviços nos níveis de promoção, proteção e/ou recuperação da saúde;

Considerando que o Assistente Social, em sua prática profissional contribui para o atendimento das demandas imediatas da população, além de facilitar o seu acesso às informações e ações educativas para que a saúde possa ser percebida como produto das condições gerais de vida e da dinâmica das relações sociais, econômicas e políticas do País;

Considerando que, para a consolidação dos princípios e objetivos do Sistema Único de Saúde, é imprescindível a efetivação do Controle Social e o Assistente Social, com base no seu compromisso ético-político, tem focalizado suas atividades para uma ação técnicopolítica que contribua para viabilizar a participação popular, a democratização das instituições, o fortalecimento dos Conselhos de Saúde e a ampliação dos direitos sociais;

(CFESS, Resolução nº 383/99).

O CFESS, ao emitir a resolução citada acima, veio ratificar a Resolução do CNS de $\mathbf{n}^{\circ}$ 218, de 06 de março de 1997, que reconhece, dentre outras profissões o Assistente Social como profissional de saúde.

Em 2009, o CFESS, elabora, com a participação de assistentes sociais de todo o Brasil e através de um amplo processo de mobilização, o documento intitulado: Parâmetros para Atuação de Assistentes Sociais na Política de Saúde, como forma de sistematizar e fortalecer as ações profissionais neste espaço sócio ocupacional.

Pensar na atuação do Assistente Social na saúde é pensar a forma como este foi inserido e como passa a ter importância para esta área, sem deixar de entender que ao longo dos anos o Serviço Social sofreu inúmeras mudanças, levando o profissional a uma ruptura com as ideias conservadoras do inicio da profissão e assumindo uma posição crítica.

\section{O ASSISTENTE SOCIAL NA ATENÇÃO PRIMÁRIA À SAÚDE}

Cada vez mais o Assistente Social possui espaço privilegiado na área de saúde, tendo um papel importante nas equipes multiprofissionais da Atenção Primária à Saúde. Assim,

Política de saúde. Revista Revise, vol. 3, Dossiê de Gestão em Saúde, p.1-17. 

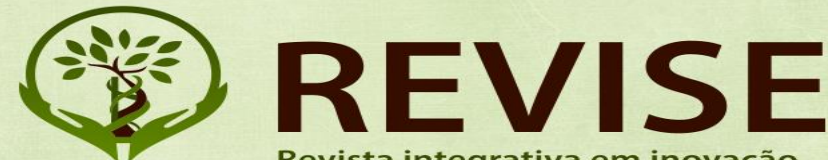

Revista integrativa em inovação tecnológica nas ciências da saúde

ISSN: $2179-6572$
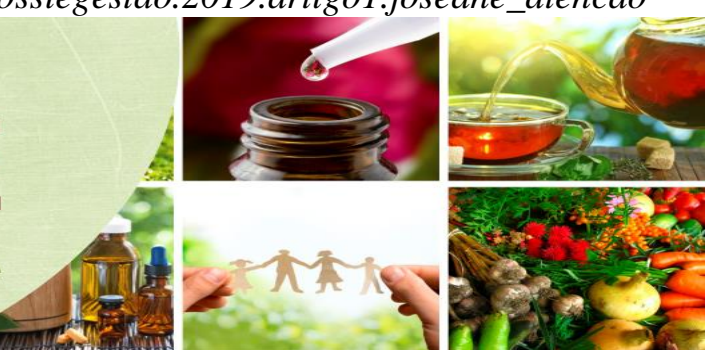

estes profissionais podem ser encontrados no planejamento e gestão de serviços nas várias unidades de saúde e no âmbito das secretarias municipal e estadual de saúde e no atendimento direto ao usuário, nos CAPs; nas Unidades de Saúde da Família e nas equipes matriciais, ao lado de profissionais de diferentes áreas de conhecimento que atuam de maneira integrada nos Núcleo de Apoio à Saúde da Família - NASF.

A política de saúde é responsável pela absorção de parte dos trabalhadores e trabalhadoras de serviço social, e apesar de ser considerada uma profissão liberal, o/a Assistente Social em sua maioria, é impulsionado pelo mercado a assumir outro lugar, o de trabalhador assalariado, dependente de uma relação de trabalho que muitas vezes coloca limites a sua intervenção profissional. (Hoffmann, Oliveira e Reidel 2017).

A atuação profissional deve ser pautada nos dispositivos que regulamentam a profissão, com abordagens voltadas para os interesses dos usuários do sistema, ou seja, defendendo os interesses da classe trabalhadora. No âmbito da saúde, o serviço social, além dos princípios norteadores contidos no Código de Ética Profissional, deve estar vinculado aos princípios defendidos pelo movimento da reforma sanitária, consolidados pelo Sistema Único de Saúde, na busca de uma melhor equidade de direitos para a população usuária, dos serviços de saúde.

O profissional em serviço social como parte de uma equipe multiprofissional deve planejar gerenciar e executar as ações de acordo com os programas estratégicos da política de saúde, apesar de ter pouca autonomia nas unidades da atenção primária. O Profissional deve, no entanto ter conhecimento no campo da saúde coletiva, destacando-se as disciplinas das ciências sociais e humanas, naturais e da saúde.

Neste sentido, o Código de Ética do Assistente Social, em seu Capítulo I, que aborda as relações com os usuários, destaca no Artigo $5^{\circ}$ os seguintes deveres:

a) Contribuir para a viabilização da participação efetiva da população usuária nas decisões institucionais;

b) Garantir a plena informação e discussão sobre as possibilidades e consequências das situações apresentadas, respeitando democraticamente as decisões dos usuários, mesmo que sejam contrárias aos valores e as crenças individuais dos profissionais, resguardados os princípios deste Código;

c) Democratizar as informações e o acesso aos programas disponíveis no espaço institucional, como um dos mecanismos indispensáveis à participação dos usuários;

Política de saúde. Revista Revise, vol. 3, Dossiê de Gestão em Saúde, p.1-17. 


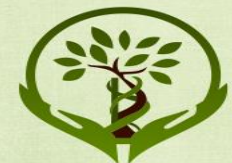

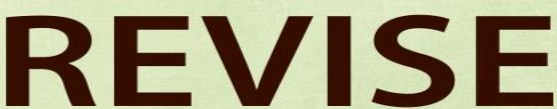

Revista integrativa em inovação tecnológica nas ciências da saúde

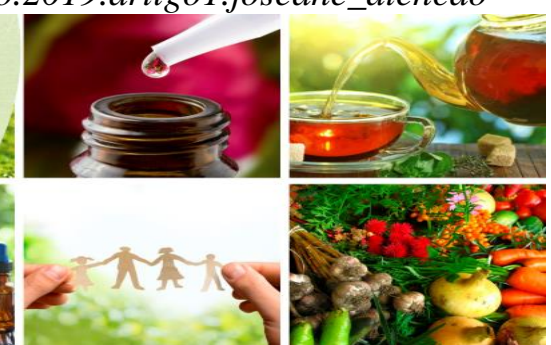

(1)

d) Devolver as informações colhidas nos estudos e pesquisas aos usuários, no sentido de que estes possam usá-las para o fortalecimento de seus interesses;

e) Informar a população usuária sobre a utilização de materiais de registro audiovisual e pesquisas a elas referentes e a forma de sistematização dos dados obtidos;

f) Fornecer a população usuária, quando solicitado informações concernente ao trabalho desenvolvido pelo Serviço Social e as suas conclusões, resguardado o sigilo profissional;

g) Contribuir para a criação de mecanismos que venham desburocratizar a relação com os usuários, no sentido de agilizar e melhorar os serviços prestados;

h) Esclarecer aos usuários, ao iniciar o trabalho, sobre os objetivos e amplitude de sua atuação profissional (SANTINI, et al, 2009, p. 100-101).

Os desafios são muitos e a responsabilidade de construir a efetivação do SUS e de seus princípios é enorme. Em tempos atuais o Sistema Único de Saúde vem sofrendo inúmeros desafios, que colocam em risco sua viabilidade e impede que ele cumpra de fato seu papel de garantia universal de saúde pública de qualidade a toda população brasileira, dentre eles se destacam, a implementação, implantação, financiamento e gestão do SUS, dificuldades de alguns gestores, em gerir o sistema, que muitas das vezes se preocupam mais em promover campanha de cunho político, do que com a saúde do cidadão, levando dessa forma falha no sistema. Neste cenário de desafios o assistente social surge como profissional que tem o papel de se articular com os demais profissionais da saúde, na luta para a devida efetivação dos direitos defendidos pela reforma sanitária que não pode ser encarada como um movimento acabando, mas que se encontra em constante renovação.

O assistente Social no SUS é o profissional cujo exercício profissional está permeado pelas tentativas de equacionar direitos, reivindicações e necessidades da população, demandante à falta de resolutividade das reivindicações do setor desde os procedimentos mais simples até os mais complexos (SANTINI, 2009, p. 48).

O serviço social possui como objeto de trabalho as expressões da questão social, ou seja, o conjunto das desigualdades sociais engendradas na sociedade capitalista. Segundo Iamamoto (2008, p 27):

[...] o conjunto das expressões das desigualdades da sociedade capitalista madura, que têm uma raiz comum: a produção social é cada vez mais coletiva, o trabalho torna-se mais amplamente social, enquanto a apropriação dos seus frutos se mantém privada, monopolizada por uma parte da sociedade.

O serviço social, nos anos de 1980 rompe com o conservadorismo presente na profissão até então, redimensionando o seu agir profissional de forma eficaz e competente

Política de saúde. Revista Revise, vol. 3, Dossiê de Gestão em Saúde, p.1-17. 


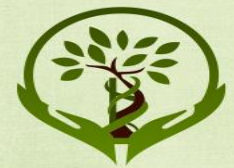

Revista integrativa em inovação

ISSN: $2179-6572$ tecnológica nas ciências da saúde
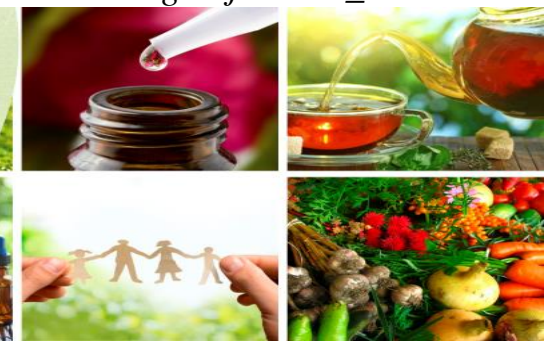

para atender as demandas tradicionais e emergentes da sociedade brasileira. $\mathrm{Na}$ contemporaneidade, o serviço social, segue com seus princípios básicos na luta pela efetivação dos direitos sociais, ofertando atendimento especializado conforme as especificidades das demandas.

A prática profissional fundamenta-se na compreensão do indivíduo dentro do seu contexto econômico, político e social, evitando ações de cunho assistencialista, paternalista que não traz efetividade na melhoria da qualidade de vida dos usuários.

Segundo Iamamoto (2008, p 200):

O Serviço Social, em sua prática, dispõe de condições potencialmente privilegiadas, pela proximidade que tem ao dia a dia das classes subalternas, de recriar aquela prática profissional nos rumos aventados, exigindo que a formação universitária possa dotar os assistentes sociais de subsídios teóricos, éticos e políticos que lhe permitam - se assim o desejarem - contribuir de mãos dadas, para o trajeto histórico em rumo aos novos tempos.

Iamamoto (2008, p 200), diz ainda:

[...]colocar os direitos sociais como foco do trabalho profissional é defendê-los tanto em sua normatividade legal, quanto traduzi-los praticamente, viabilizando a sua efetivação social. Essa é uma das frentes de luta que move os assistentes sociais nas micro ações cotidianas que compõem o seu trabalho.

No campo da saúde, a atuação do assistente social é voltada para mediações, aonde os usuários chegam com problemas pré-estabelecidos: direitos violados e ameaçados; sofrimentos, perdas, dor, desconhecimento, dentre outros e que necessitam para a sua intervenção da compreensão dos aspectos sociais, econômicos, culturais de cada usuário demandatário dos serviços de saúde.

Segundo CEFSS, conforme o Parâmetro do Assistente Social na Saúde, p 39:

[...]os assistentes sociais na saúde atuam em quatro grandes eixos: atendimento direto aos usuários; mobilização, participação e controle social; investigação, planejamento e gestão; assessoria, qualificação e formação profissional.

Ante o exposto, o trabalho do Assistente Social no campo da saúde possui uma grande importância, em particular na atenção primária, sendo o momento do primeiro contato entre o profissional com o individuo, que em muitas vezes chega confuso, fragilizado necessitando de atenção e cuidados especializados.

Política de saúde. Revista Revise, vol. 3, Dossiê de Gestão em Saúde, p.1-17. 


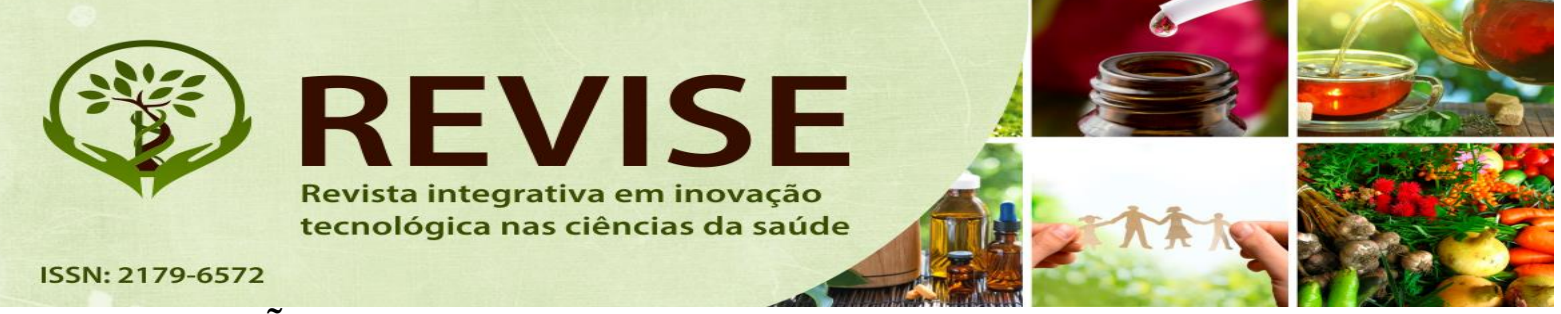

CONSIDERAÇÕES FINAIS

O presente trabalho teve como objetivo conhecer o papel do Serviço Social na Atenção Primária à Saúde.

A análise teve como ponto de partida a concepção de saúde como direito universal, entretanto, existe uma linha abissal entre o direito que está assegurado no marco legal do SUS e a sua efetivação e acesso por parte de todos os cidadãos. O SUS completará 30 anos em outubro deste ano e apesar de alguns avanços está longe de ser o SUS constitucional.

A concepção de saúde que o serviço social partilha é aquela pautada na visão ampliada de saúde, ou seja, leva em conta não só a ausência de doença, mas os aspectos condicionantes e determinantes da saúde, bem como o caráter de direito social e responsabilidade do Estado. A promoção de saúde e a prevenção de doenças são as dimensões privilegiadas nas ações desenvolvidas, no âmbito da atenção básica do Sistema Único de Saúde (SUS).

Como a equipe multiprofissional planeja, gerencia e executam as ações de acordo com os programas estratégicos da política de saúde, o Assistente Social dispõe de pouca ou nenhuma autonomia no âmbito das unidades da atenção primária. Entre os conhecimentos do campo da saúde coletiva, julgados necessários para o exercício profissional do assistente social na atenção primária, destacam-se as disciplinas das ciências sociais e humanas, naturais e da saúde. $\mathrm{O}$ exercício profissional nas unidades da atenção básica em saúde deve visar à promoção da integralidade, da interdisciplinaridade e da intersetorialidade, sob pena de reproduzir práticas profissionais tradicionais, situação evidenciada pelas diversas categorias profissionais, como condição a ser superada. Não se trata de um caminho a ser trilhado à parte da equipe multiprofissional, mas uma tarefa a ser efetivada de forma articulada ao processo de trabalho e distintos saberes que conformam o campo interdisciplinar da saúde coletiva.

O Assistente Social enfrenta, na atualidade, o desafio de não ser apenas um profissional executivo, mas que ultrapassa os limites das atividades burocráticas e tarefas estabelecidas, trabalhando com as questões sociais bem como com a garantia do acesso a saúde para os usuários, aqueles que eles constatam que estão em estado de vulnerabilidade social.

Política de saúde. Revista Revise, vol. 3, Dossiê de Gestão em Saúde, p.1-17. 


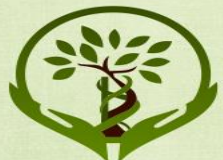

ISSN: $2179-6572$

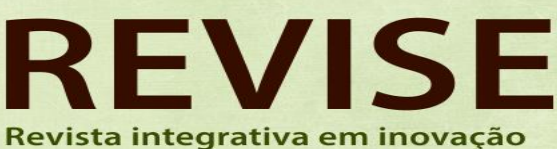
Revista integrativa em inovação
tecnológica nas ciências da saúde

Estabelecido pela Constituição Federal de 1988, a saúde é um direito com garantias mediante políticas sociais e econômicas que visam à redução do risco de doença. $\mathrm{O}$ acesso é universal e igualitário, no entanto isto esta longe de ser uma realidade, pois diversos tratamentos que demandam alta complexidade e elevado custo ainda não são ofertados na rede pública com tanta facilidade o que leva os usuários a procurarem a Justiça para que esta faça com que o Estado cumpra a lei e custei o referido tratamento

Nesse contexto o Assistente Social pode entrar como interventor do usuário na busca das melhores soluções para resolução do caso, visto que seu papel também é desempenhar suas atividades profissionais, com eficiência e responsabilidade, observando a legislação em vigor.

O desafio do Assistente Social é se desvencilhar do que é burocrático e priorizar as requisições institucionais em favor do que é necessário fazer, sendo as demandas do usuário prioridade. A atenção prestada pelo Assistente Social permite aos usuários que eles se sintam respeitados, apoiados e assistidos, pois estes contribuem para ampliar, facilitar e realizar o acesso aos direitos. Na rotina do assistente social, nada é planejado nem sistematizado, pois a variação de demanda dita o que será feito, orientação, encaminhamento, aconselhamento, apoio. Assim, o serviço desse profissional pode trazer ganhos aos usuários que é o que mais importa a promoção e efetivação de uma saúde de qualidade.

Portanto, através das especificidades de intervenção do serviço social existe uma clara importância da atuação deste profissional no sentido de fortalecer a atenção básica.

Política de saúde. Revista Revise, vol. 3, Dossiê de Gestão em Saúde, p.1-17. 


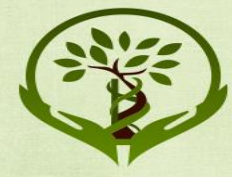

ISSN: $2179-6572$

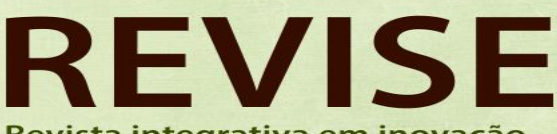

Revista integrativa em inovação tecnológica nas ciências da saúde

\section{REFERÊNCIAS}

ASSUMPÇAO, Patrícia Freitas Schemes. A integralidade em saúde e o debate do serviço social. Florianópolis, 2007. 114p. Acessado em: 12 de setembro de 2017. Disponível em: www.assistentesocial.com.br.

ÁVILA, Heleni Duarte Dantas de. A construção do SUS na Bahia: uma história da sua implementação - 1986 a 2006. 2013. 238p. Tese (Doutorado em Saúde Pública). Salvador: Instituto de Saúde Coletiva - UFBA, 2013.

BRASIL. Ministério de Saúde. Política Nacional de Atenção Básica. Portaria $\mathbf{n}^{\mathbf{0}} \mathbf{2 . 4 8 8}$, de 21 de outubro de 2011. Acessado em: 29 de novembro de 2017. Disponível em: http://bvsms.saude.gov.br/bvs/saudelegis/gm/2011/prt2488_21_10_2011.html

BRASIL. Resolução CFESS N. ${ }^{\circ}$ 383/99 de 29 de Março de 1999. EMENTA: Caracteriza o assistente social como profissional da saúde. Acessado em 24 de Novembro de 2017. Disponível em http://www.cfess.org.br/arquivos/resolucao_383_99.pdf

BRASIL. Política Nacional de Atenção Básica. Portaria n 2436/GM/MS, de 21 de setembro de 2017. Acessado em: 01/06/2018. Disponível em: http://bvsms.saude.gov.br/bvs/saudelegis/gm/2017/MatrizesConsolidacao/comum/250584.ht $\underline{\mathrm{ml}}$

BRAVO. A Política de Saúde no Brasil. Serviço Social e Saúde: formação e trabalho profissional. Disponível em: http://www.fnepas.org.br/pdf/servico_social_saude/texto15.pdf. Acessado em 20 de Maio de 2018.

BOGADO, Franciele Toscan; CASTELO BRANCO, Patrícia Martins. Fundamentos histórico, teóricos e metodológicos do Serviço Social I. São Paulo: Pearson Prentice Hall, 2009. $174 \mathrm{p}$

CAMARGO, Marisa. Configurações do Trabalho do Assistente Social na Atenção Primária em Saúde (APS) no Século XXI: um estudo da produção teórica do serviço social. 2014. Disponível em: http://repositorio.pucrs.br/dspace/bitstream/10923/5822/1/000457557Texto\%2BCompleto-0.pdf. Acessado em 10 de dezembro de 2017.

CFESS. Resolução N. ${ }^{0}$ 383/99 de 29/03/1999, "Caracteriza o assistente social como profissional da saúde". Disponível em: www.cfess.org.br. Acessado em: 05/12/2017.

GALVÃO CM, SAWADA NO, TREVIZAN MA. Revisão sistemática: recurso que proporciona a incorporação das evidências na prática da enfermagem. Rev Latino-am Enfermagem 2004 maio-junho; 12 (3):549-556. Disponível em: http://www.scielo.br/pdf/rlae/v12n3/v12n3a14.pdf. Acesso em: 20/12/2017.

Política de saúde. Revista Revise, vol. 3, Dossiê de Gestão em Saúde, p.1-17. 


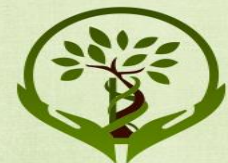

ISSN: $2179-6572$

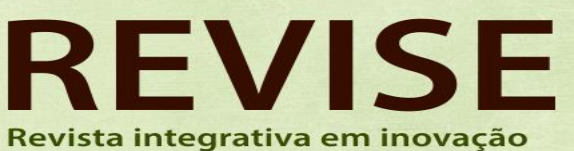

tecnológica nas ciências da saúde
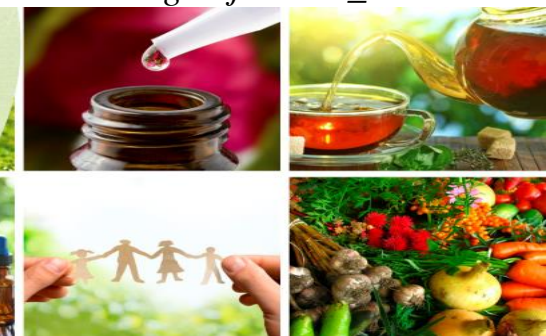

HOFFMANN, Edla; OLIVEIRA, Sheyla Priscila Souza; REIDEL, Tatiana. O Trabalho do Assistente (a) Social na Atenção Básica: dilemas e perspectivas no município de Natal/RN. Disponível

em: http://www.seer.ufal.br/index.php/coloquiocintas/article/view/3715/2633. Acessado em 10 de dezembro de 2017.

IAMAMOTO, M.V. O serviço social na contemporaneidade: trabalho e formação profissional. 15. ed. São Paulo, Cortez 2008.

LAVRAS, Carmen. Atenção primária à saúde e a organização de redes regionais de $\begin{array}{llllll}\text { atenção à } & \text { saúde } & \text { no } & \text { Brasil. } & \text { Disponível } & \text { em: }\end{array}$ http://www.scielo.br/scielo.php?script=sci_arttext\&pid=S0104-12902011000400005.

Acessado em: 25 de novembro de 2017

Lei 8.080/90. Dispõe sobre as condições para a promoção, proteção e recuperação da saúde, a organização e o funcionamento dos serviços correspondentes e dá outras providências. Acessado em: 22/12/2017. Disponível em: www.mds.ba.gov.br.

Lei 8.662 de 7 de junho de 1993. Dispõe sobre a profissão de Assistente Social e dá outras providências. Acessado em: 18/12/2017. Disponível em: www.planalto.gov.br.

KRÜGER, Tânia Regina. SUS: da perda da radicalidade democrática ao novo desenvolvimentismo. Revista katalysis, Florianópolis, v. 17, n.2, p.218-226, jul./dez. 2014. Disponível em:< http://www.scielo.br/pdf/rk/v17n2/1414-4980-rk-17-02-0218.pdf >>>>. Acessado em: 10 de Dezembro de 2017.

MATTA Gustavo Corrêa; MOROSINI, Márcia Valéria Guimarães. Atenção Primária à Saúde. Disponível em: http://www.epsjv.fiocruz.br/dicionario/verbetes/ateprisau.html. Acessado em 22 de Novembro de 2017.

MARQUES, Glenda Lindaura. O serviço Social no NASF: as condições de trabalho e as demandas do exercício profissional. Acessado em 24 de Novembro de 2017. Disponível em: https://repositorio.ufsc.br/xmlui/bitstream/handle/123456789/175296/TCC\% 20\%20Glenda\%20L\%20Marques.pdf?sequence $=1 \&$ is Allowed $=y$

MEDEIROS, Larissa. O Serviço Social no NASF: Demandas, respostas e desafios profissionais. Disponível em: https://repositorio.ufsc.br/bitstream/handle/123456789/103590/TCC\%20\%20Larissa\%20Medeiros.pdf?sequence $=1$. Acessado em 14 de Janeiro de 2018.

Ministério da Saúde. Resolução no218 de 06 de março de 1997. Acessado em: 25/12/2017. Disponível em: www.datasus.gov.br.

Política de saúde. Revista Revise, vol. 3, Dossiê de Gestão em Saúde, p.1-17. 


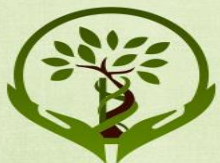

ISSN: $2179-6572$

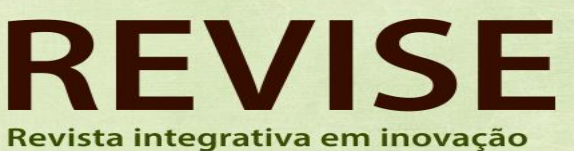
tecnológica nas ciências da saúde
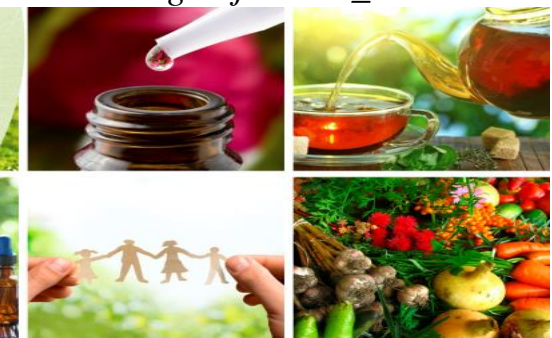

PAIM, J S. Modelos de atenção e vigilância da saúde. In: Rouquayrol MZ, Almeida FN, organizadores. Epidemiol e Saúde. $6^{a}$ ed. Rio de Janeiro: MEDSI; 2003. p. 567-586

Parâmetros para a atuação de Assistentes Sociais na Saúde. Brasília,

2010.

Disponível

em:

http://www.cfess.org.br/arquivos/Parametros_para_a_Atuacao_de_Assistentes_Sociais_na_Sa ude.pdf Acessado em 20 de abril de 2018.

SANTINI, Maria Angela; GÓES, Adarly Rosana Moreira. Ética profissional: serviço social. São Paulo: Pearson Prentice Hall, 2009. 182 p.

SANTINI, Maria Ângela. Políticas Sociais III: Serviço Social. São Paulo: Pearson Prentice Hall, 2009. 181p.

SODRE, Francis. O Serviço Social entre a prevenção e a promoção da saúde: tradução, vinculo e acolhimento. Disponível em: http://www.scielo.br/pdf/sssoc/n117/05.pdf. Acessado em: 10 de dezembro de 2017.

VASCONCELOS, Ana Maria de. Serviço Social e Práticas Democráticas na Saúde. Disponível em: http://www.fnepas.org.br/pdf/servico_social_saude/texto2-5.pdf Acessado em 20 de maio de 2018.

ZANIN, Gabriela. NASF, campo de intervenção do Serviço Social: possibilidades e desafios na efetivação da Política Nacional de Atenção Básica. Disponível em: http://www.lume.ufrgs.br/handle/10183/157441. Acessado em 14 de Janeiro 2018.

Política de saúde. Revista Revise, vol. 3, Dossiê de Gestão em Saúde, p.1-17. 